\title{
Aa. Vv., «Bulletin d'Informations Proustiennes», 37
}

\section{Geneviève Henrot Sostero}

\section{(2) OpenEdition}

\section{Journals}

\section{Edizione digitale}

URL: http://journals.openedition.org/studifrancesi/8355

DOI: 10.4000/studifrancesi.8355

ISSN: 2421-5856

\section{Editore}

Rosenberg \& Sellier

\section{Edizione cartacea}

Data di pubblicazione: 1 mai 2009

Paginazione: 205

ISSN: 0039-2944

\section{Notizia bibliografica digitale}

Geneviève Henrot Sostero, «Aa. Vv., «Bulletin d'Informations Proustiennes», 37», Studi Francesi [Online], 157 (LIII | I) | 2009, online dal 30 novembre 2015, consultato il 08 janvier 2021. URL: http:// journals.openedition.org/studifrancesi/8355 ; DOI: https://doi.org/ERREUR PDO dans /localdata/ www-bin/Core/Core/Db/Db.class.php L.34 : SQLSTATE[HY000] [2006] MySQL server has gone away

Questo documento è stato generato automaticamente il 8 janvier 2021.

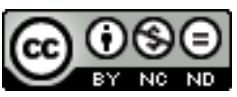

Studi Francesi è distribuita con Licenza Creative Commons Attribuzione - Non commerciale - Non opere derivate 4.0 Internazionale. 


\title{
Aa. Vv., «Bulletin d'Informations Proustiennes», 37
}

\author{
Geneviève Henrot Sostero
}

\section{NOTIZIA}

«Bulletin d'Informations Proustiennes», 37, 2007, pp. 200.

1 Quasi quarant'anni di ricerca genetica rappresentano un capitolo consistente della storia della critica proustiana. Eppure non cessano di venire alla luce nuovi inediti, tra cui due lettere di A. Nahmias e due lettere di M. Proust in cui «l'homme de confiance»e «l'homme de lettres» si scambiano informazioni utili alla stesura del grande romanzo (Pyra WISE, Marcel Proust et Albert Nahmias: quelques lettres inédites, pp. 9-30). Sorprendono ancora certi episodi puntuali del romanzo che, riletti in stretta prospettiva avantestuale, rivelano il tardivo formarsi dell'assetto narrativo che conosciamo (Laurence TEYSSANDIER, La Rencontre de Charlus et de Morel sur le quai de la gare de Doncières: une réécriture de dernière minute, pp. 31-44).

Il dossier centrale di questo numero riproduce gli interventi dell'ultimo seminario Proust et le style, svoltosi presso l'École Normale Supérieure (ITEM, Equipe Proust), nell'a.a. 2005-2006. Vengono considerati diversi aspetti pertinenti alla critica genetica quali, nella linea più classica della critica storica, le influenze stilistiche, possibili o accertate, dei predecessori: Philippe CHARDIN, in Proust et ses "surmoi" classiques et flaubertiens (pp. 47-58) riascolta Racine, Montaigne, Shakespeare, Hugo, Flaubert con orecchio proustiano in cerca di armoniche ora barocche ora romantiche. Jean MiLly insegue alcune Pistes génétiques du style de Proust attraverso tre campioni: un pastiche di Henri de Régnier, il brano delle camere in Combray, il tinello di Françoise visto dal giardino (pp. 59-76). Trattare lo stile in relazione a Proust significa il più delle volte chiedersi cosa pensasse lo scrittore dello stile in generale, di uno stile in particolare, oppure della retorica (Stéphane CHAUDIER, Proust et la rhétorique, pp. 77-88). Altri tentano un confronto più induttivo con il testo, ripercorrendo le variazioni successive di un 
medesimo episodio (RTP III, pp. 911-912: Michel SANDRAS, Variations sur une phrase de "La Prisonnière", pp. 89-99). Marion SCHMID si chiede quali possano essere l'entità e la natura dell'influenza decadentista sull'immaginario e sullo stile proustiano (Proust et le style décadent, pp. 101-116). Un aspetto ancora poco studiato, l'ironia, invita a considerare la questione dello stile sotto un punto di vista insolito: Sophie DUVAL, con Une "farce poétique": les anneaux du style et les alliances de l'humour , pp. 117-132, fa apprezzare l'originalità profonda della lettura proustiana elaborata nella sua tesi di dottorato (L'Ironie proustienne. La vision stéréoscopique, Paris, Champion, 2004).

3 Altri studi offrono letture più psicologiche degli esordi testuali: Inge CROSMAN WIMMERS, con Autour d'un paradigme affectif: Proust et le "modèle d'amour familial" (pp. 135-144), conferma il suo interesse per l'emozione nell'opera proustiana, sviluppato con più ampio respiro in Proust and Emotion. The Importance of Affect in "À la recherche du temps perdu" (Toronto-Buffalo-London, University of Toronto Press, 2003).

LUC FRAISSE ricostituisce la genealogia epistemologica del concetto di croyance in Proust, tra Kant, Schopenhauer, Schelling, Comte e Séailles, confrontandosi con le interpretazioni storico-filosofiche che attraversano tutta la critica proustiana, da Fernandez, Maurois, Poulet a S. Chaudier, passando per De Lattre, Jauss, Bataille, A. Henry e A. Simon (La Notion de croyance chez Proust: état d'une question problématique, pp. 145-158).

5 Anche la formazione giuridica di Marcel Proust, di assetto universitario, consente di ricollegare l'indagine storico-biografica e l'indagine tematica: sembra che intervenga certa visione giuridica nella concezione proustiana del tempo e nel concetto di "patto" sul quale poggiano i rapporti familiari tra il narratore, sua madre e sua nonna (Laurence DEPAMBOUR-TARRIDE, Proust et le droit: premières approches, pp. 159-174).

6 La quarta parte del numero riepiloga le attività proustiane dell'anno: vendite di manoscritti, eventi, convegni, pubblicazioni, lavori in corso. 